\title{
Human metapneumovirus in Southern Brazil
}

\author{
Tatiana Schäffer Gregianini ${ }^{[1]}$, Claudete Farina Seadi ${ }^{[1]}$, Ivone Menegolla ${ }^{[2]}$, \\ Letícia Garay Martins ${ }^{[2]}$, Nilo Ikuta ${ }^{[3]}$, Jonas Michel Wolf ${ }^{3]}$ \\ and Vagner Ricardo Lunge ${ }^{[3]}$
}

[1]. Laboratório Central do Estado do Rio Grande do Sul, Secretaria de Saúde do Estado do Rio Grande do Sul, Porto Alegre, RS, Brasil. [2]. Centro Estadual de Vigilância em Saúde, Secretaria de Saúde do Estado do Rio Grande do Sul, Porto Alegre, RS, Brasil.

[3]. Laboratório de Diagnóstico Molecular, Universidade Luterana do Brasil, Canoas, RS, Brasil.

\begin{abstract}
Introduction: Infections caused by respiratory viruses are important problems worldwide, especially in children. Human metapneumovirus (hMPV) is a respiratory pathogen and causes severe infections with nonspecific symptoms. This study reports the hMPV occurrence and dissemination in southern Brazil and compares the frequency of occurrence of this virus and the human respiratory syncytial virus (hRSV) in the epidemiological weeks in a three-year period (2009-2011). Methods: In total, 545 nasopharyngeal (NP) specimens from individuals with Severe Acute Respiratory Syndrome (SARS) who were negative for other seven respiratory viruses were analyzed for the presence of hMPV. Human metapneumovirus was detected by direct immunofluorescence and real-time reverse transcription polymerase chain reaction. Results: hMPV was detected in 109 patients from the main geographic regions of the southernmost state of Brazil, presenting similar overall prevalence in males $(46.8 \%)$ and females (53.2\%). Among children who were less than six years old, hMPV was detected in 99 samples of all age groups, with a higher frequency in infants who were less than one year old (45.7\%) compared to all other age groups until six years. hMPV and hRSV infection occurred in almost the same epidemiological weeks (EWs) of each year, with peaks of incidence between EW 31/37 and EW 26/38 for the years 2009 and 2011, respectively. hMPV was further detected in several cases of SARS and it was the only virus detected in three deaths. Conclusions: These findings indicate that hMPV is in circulation in southern Brazil and highlight the importance of diagnosing hMPV for influenza-like illness in the population.
\end{abstract}

Keywords: Human metapneumovirus. Human respiratory syncytial virus. Epidemiology. Respiratory viruses.

\section{INTRODUCTION}

Viral respiratory infections are global health problems because of their dissemination in the community, ubiquitous distribution, and ability to cause high morbidity in children and adults with immunosuppression ${ }^{1,2}$. Severe acute respiratory syndrome (SARS) is a more serious outcome of viral respiratory infections, and the clinical symptoms are dyspnea, fever, myalgia, lethargy, cough, and sore throat ${ }^{3}$. SARS patients are mostly infants and immunocompromised individuals and require special care in emergency rooms of hospitals because of respiratory complications (bronchiolitis, pneumonia, etc.), resulting in substantial cost to the affected families in particular and society in general ${ }^{4-7}$. These infections disseminate more in cold climates, but also occur in tropical countries, with the highest frequency of occurrence between autumn and spring ${ }^{8,9}$.

Corresponding author: MSc. Jonas Michel Wolf.

e-mail: jonasmwolf@gmail.com

Received 9 November 2017

Accepted 22 December 2017
Several virus species cause respiratory infections, such as influenza, parainfluenza, adenovirus, coronavirus, bocavirus, human rhinovirus, human enterovirus, human respiratory syncytial virus (hRSV, recently renamed human orthopneumovirus) and human metapneumovirus (hMPV) ${ }^{1}$. hMPV is one of the youngest respiratory viruses (together with bocavirus) since it was identified in the Netherlands in the beginning of this century ${ }^{10}$. In Latin America, hMPV was first detected in children younger than three years in northeast Brazil ${ }^{11}$. hMPV is currently classified into the genus Metapneumovirus, subfamily Pneumovirinae, and family Paramyxoviridae. It is an enveloped, segmented, and pleomorphic virus with a negative sense RNA genome of approximately 13,000 nucleotides ${ }^{1}$.

Epidemiological data demonstrated that the frequency of hMPV occurrence ranges from $1.5-43 \%$, according to the population group and geographic region ${ }^{12-16}$. hMPV cases are also more frequent in winter and spring, usually occurring together with hRSV outbreaks $s^{1,2,12,14}$. In viral respiratory diseases, hMPV frequency ranges from $5.6 \%$ to $20.1 \%$ as demonstrated by independent studies in different Brazilian cities $^{14,15-19}$. Similar frequencies have been observed in other South American countries ${ }^{20-23}$. hMPV infections in children are also much more frequent than in adults ${ }^{2}$. The main risk factors 
are age less than five years, presence of pre-existing diseases (nosocomial infection, chronic pulmonary disease, heart, and neural disorders), and immunosuppressed condition ${ }^{8,24,25}$. Patients infected with hMPV commonly present respiratory symptoms such as a cough, hypoxia, wheezing, and fever ${ }^{8,26}$. Bronchiolitis, bronchitis, pneumonia, and SARS are more serious health complications ${ }^{1}$. Children younger than two years present more worrying clinical evolution, and approximately $10 \%$ cases require hospitalization ${ }^{27,28}$.

Laboratory testing is necessary to detect and confirm an hMPV infection ${ }^{29,30}$. Culture in specific cell lines is used for isolating viruses; however, this is a fastidious and slow process to be used in clinical settings ${ }^{1,2}$. hMPV can also be detected by direct immunofluorescence (DAF) and enzyme-linked immunosorbent assay ${ }^{31}$. Reverse transcription-polymerase chain reaction (RT-PCR) is the main method for detecting hMPV because of its better analytical performance ${ }^{32}$. A combination of immunofluorescence assays and RT-PCR have been usually recommended to obtain more definitive diagnosis ${ }^{1}$.

Although hMPV infection is important, epidemiological data regarding this disease are scarce in Brazil. Routine detection of this virus is usually not performed in the main private and public laboratories involved in the investigation of respiratory infections. The present study aimed to detect hMPV in patients with SARS in a three-year period (2009 to 2011) in southern Brazil.

\section{METHODS}

\section{Sampling}

All the samples of this study were obtained from the Central Laboratory of the Rio Grande do Sul (RS) State (LACEN/RS). LACEN/RS is a public health laboratory that analyzes viral respiratory infections from clinical centers and hospitals located in different cities of the RS state. It belongs to the Brazilian network of Influenza and Other Respiratory Virus Surveillance, providing diagnostic and epidemiological data of several viruses, such as influenza virus $\mathrm{A}$ and $\mathrm{B}, \mathrm{hRSV}$, adenovirus (ADV), and parainfluenza virus types 1, 2 and 3 (PIV).

Clinical samples from 6,918 SARS cases notified by 204 hospitals (representing $66 \%$ of the state hospitals) were analyzed from January 2009 to December 2011. Influenza virus $\mathrm{A}$ was detected using $\mathrm{RT}-\mathrm{qPCR}^{3,33}$, and influenza virus $\mathrm{B}, \mathrm{hRSV}, \mathrm{ADV}$, and PIV 1, 2, and 3 were detected using indirect immunofluorescence assay (IFA) (Light Diagnostic ${ }^{\mathrm{TM}}$ Respiratory Panel 1 Viral Screening and Identification kit, Merck Millipore ${ }^{\circledR}$, Darmstadt, Germany). In total, 3,495 samples presented negative result for all these viruses, and by convenience sampling, $545(20 \%)$ were selected for hMPV detection (Figure 1). The sampling selection was performed from the time of routine analysis in the laboratory. The collection of samples from children under or five years of age and from patients who died because of respiratory complications was prioritized in 2009. However, samples of other individuals with SARS were also included in the analysis in the other two years (2010 and 2011) to evaluate hMPV prevalence and fatal cases in other age groups. Patient data (age, gender, clinical symptoms, and comorbidities) were obtained for all samples.

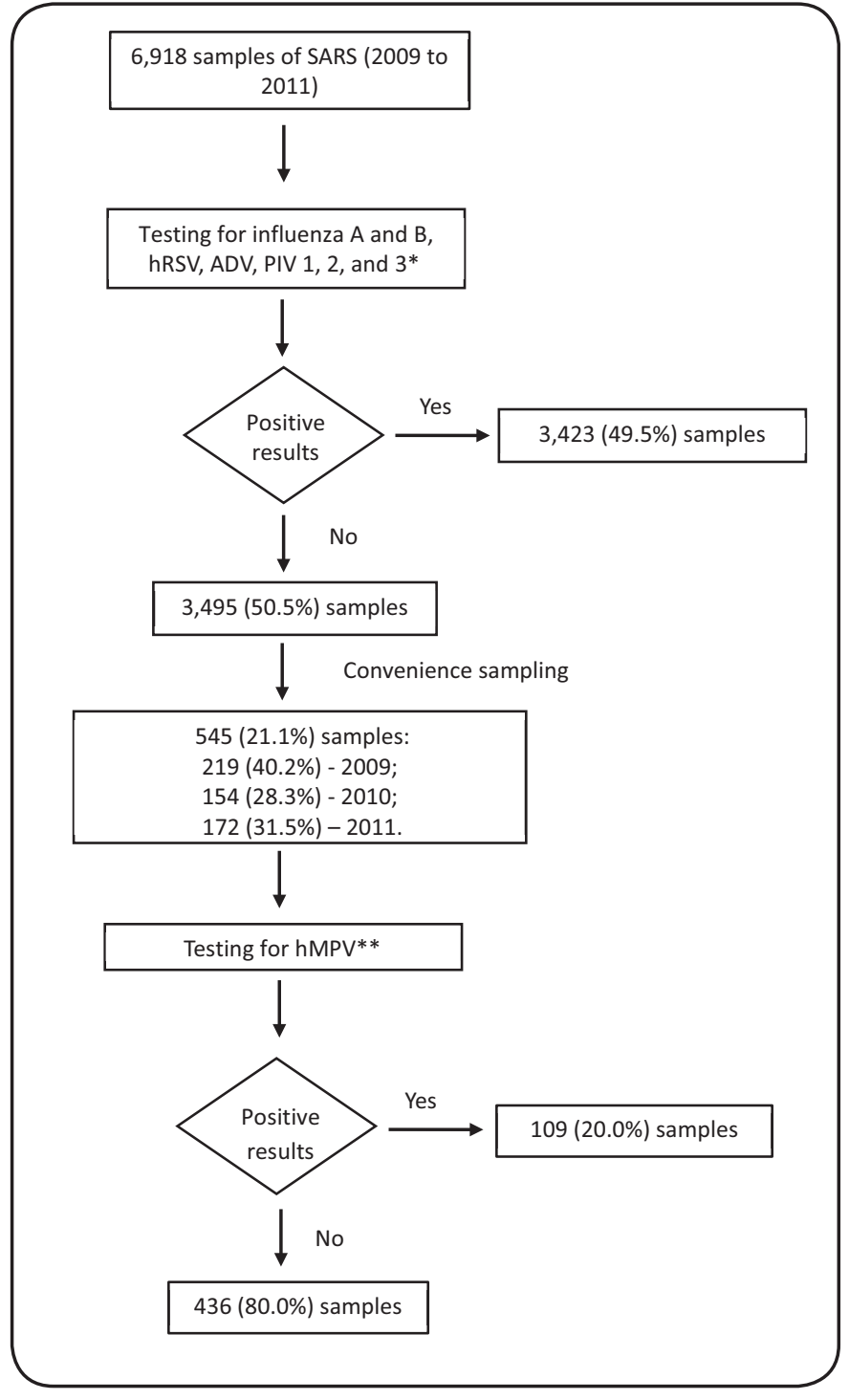

FIGURE 1: Flowchart showing samples evaluated for hMPV detection in this study from 2009-2011. SARS: severe acute respiratory syndrome; hRSV: human respiratory syncytial virus; ADV: adenovirus; PIV 1, 2, and 3: parainfluenza types 1, 2, and 3. *Influenza A virus was detected by reverse transcription-polymerase chain reaction (RT-qPCR), whereas the other viruses were detected by indirect immunofluorescence. **hMPV was detected by direct immunofluorescence (DAF) and RT-qPCR.

Further, sample collection date was registered to define the epidemiological week (EW) of the virus detection in three years.

\section{Ethical Considerations}

This study was approved by the Committee on the Ethics of the FEPPS/RS (Ethics Statement n. 11/2010).

\section{hMPV detection}

Human metapneumovirus is routinely detected by DFA and RT-qPCR in LACEN/RS as previously described ${ }^{13}$. The procedure for DFA is as follows. Cell suspension of nasopharyngeal secretion samples was distributed over the microscope slide, air-dried, and fixed with cold acetone. Were added $40 \mu \mathrm{L}(1: 1)$ 
of fluorescein isothiocyanate-labeled monoclonal antibody (Millipore ${ }^{\circledR}$ CAT.5091-approved by the Food and Drug Administration for research use only) and the samples were incubated for $15 \mathrm{~min}$ at $37^{\circ} \mathrm{C}$. The slides were washed by immersion in phosphate buffer, air-dried, mounted with buffered glycerol, and examined using a Leica DM 1000/HBO100W ${ }^{\circledR}$. In the RT-qPCR analysis, total RNA of the samples was first extracted using RNA mini kit according to the manufacturer's protocol (Qiagen, CA, USA). RT-qPCR was performed using $5 \mu \mathrm{L}$ of each RNA sample, $0.5 \mu \mathrm{L}$ of SSIII/Platinum Taq mix, $12.5 \mu \mathrm{L} 2 \times$ master mix, and the following primers and probe: F 540 (5'-CAAGTGTGACATTGCTGAYCTRAA-3'), R 598 (5'-ACTGCCGCACAACATTTAGRAA-3') and P (5'-56-FAM/ TGGCYGTYAGCTTCA GTCAATTCAACAGA-3'/TAMRA), targeting the fusion glycoprotein (F) gene from hMPV ${ }^{34}$. All reactions were performed on a StepOnePlus ${ }^{\mathrm{TM}}$ thermocycler (Applied Biosystems, CA, USA) using the following conditions: $50^{\circ} \mathrm{C}$ for $30 \mathrm{~min}, 95^{\circ} \mathrm{C}$ for $2 \mathrm{~min}$, followed by 35 cycles of $95^{\circ} \mathrm{C}$ for $15 \mathrm{~s}$ and $55^{\circ} \mathrm{C}$ for $35 \mathrm{~s}$. Positive and negative controls were used in all assays. Individuals were considered positive for hMPV if they tested positive by DFA or PCR.

\section{Statistical analysis}

Statistical Package for Social Sciences [(SPSS), version 17.0, Chicago, IL, USA] was used for statistical analyses. Qualitative variables were expressed as absolute and relative frequencies. Graphical representations were used to demonstrate the distribution of hMPV and hRSV cases in epidemiological weeks (2009-2011). Statistical differences between the ages and symptoms of patients infected with these viruses were calculated using chi-square test with significance level of $5 \%$. $p<0.05$ was considered statistically significant.

\section{RESULTS}

\section{Overall frequency of hMPV detection and fatality}

Human metapneumovirus was detected in 109 (20\%) patients from all main geographic regions of Rio Grande do Sul, the southernmost state of Brazil (Figure 2). The highest number of cases occurred in the metropolitan region of the capital State Porto Alegre with a total of 74 (67.9\%) samples; however, hMPV was also detected in other zones of this state, mainly in the northern and the valley regions.

The overall characteristics of hMPV-positive cases are shown in Table 1. Prevalence of hMPV infection showed a similar distribution for males $(\mathrm{n}=51,46.8 \%)$ and females $(\mathrm{n}=58,53.2 \%)$. hMPV infection predominated in children less than six years of age as it was detected in $99(90.8 \%)$ samples in all age groups from 0 to 6 years. Further, hMPV frequency was much higher in infants less than 1 year of age $(n=43,39.4 \%)$, but it was also detected in all age groups until 6 years $(n=21$; $19.3 \%$ in 1 -year-old group, $\mathrm{n}=30 ; 27.5 \%$ in $2-4$ year-old group, and $n=5,4.6 \%$ in 5-6-year-old group). The ten remaining cases were distributed among people of five different age groups:

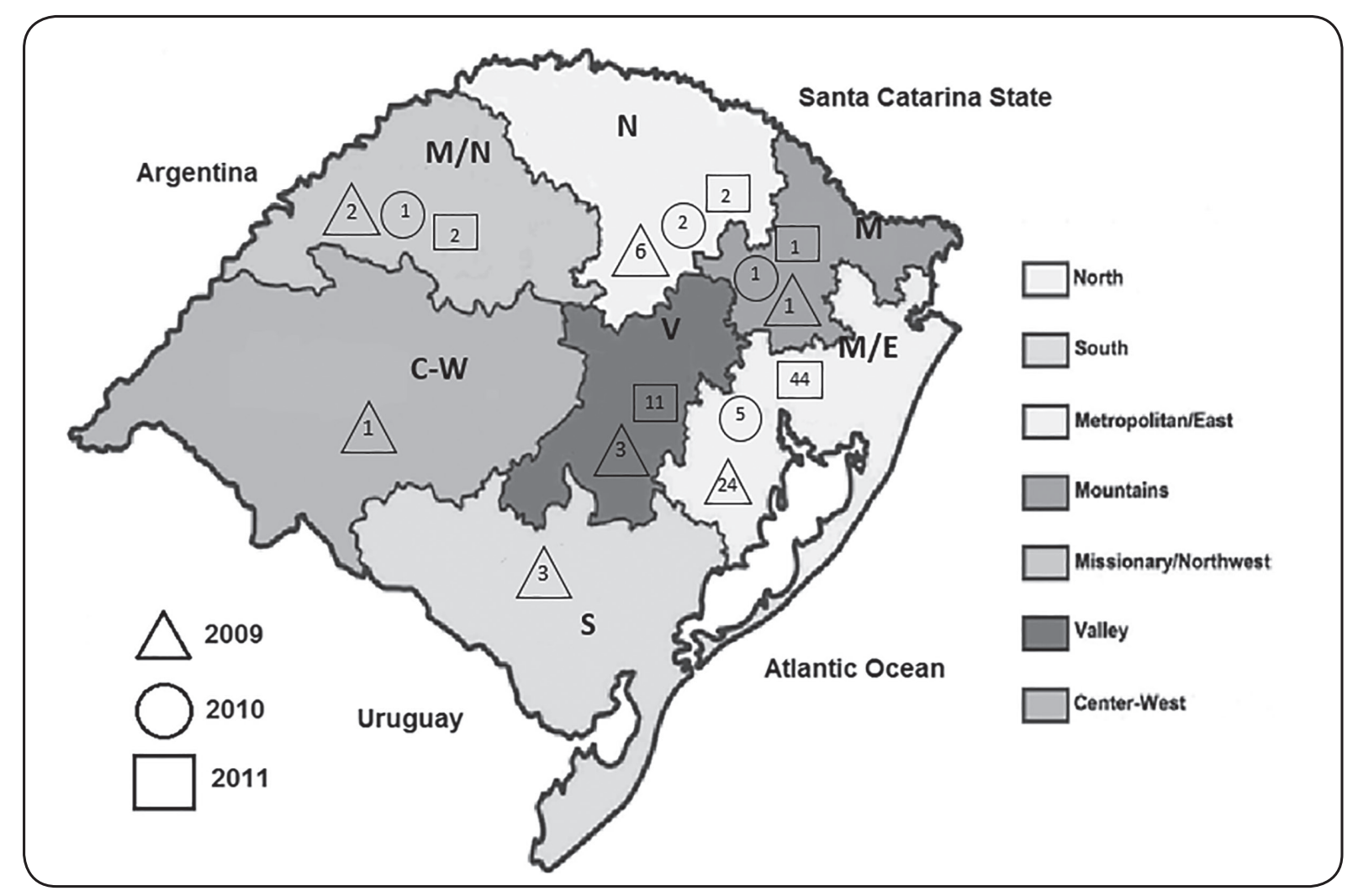

FIGURE 2: Distribution of hMPV cases in Rio Grande do Sul State, Brazil, from 2009 to 2011. hMPV: human metapneumovirus. 
TABLE 1: Demographic characteristics of human metapneumovirus-positive patients in South Brazil, $2009-2011$.

\begin{tabular}{|c|c|c|c|c|c|c|c|c|}
\hline \multirow{3}{*}{ Variables } & \multicolumn{6}{|c|}{ Years of study } & \multirow{2}{*}{\multicolumn{2}{|c|}{ Total }} \\
\hline & \multicolumn{2}{|c|}{2009} & \multicolumn{2}{|c|}{2010} & \multicolumn{2}{|c|}{2011} & & \\
\hline & $\mathrm{n}$ & $\%$ & $\mathbf{n}$ & $\%$ & $\mathrm{n}$ & $\%$ & $\mathbf{n}$ & $\%$ \\
\hline $\begin{array}{l}\text { Human me } \\
\text { cases }\end{array}$ & 40 & 36.7 & 9 & 8.3 & 60 & 55.0 & 109 & 100.0 \\
\hline \multicolumn{9}{|l|}{ Gender } \\
\hline male & 24 & 22.0 & 7 & 6.4 & 27 & 24.8 & 58 & 53.2 \\
\hline female & 16 & 14.7 & 2 & 1.8 & 33 & 30.3 & 51 & 46.8 \\
\hline \multicolumn{9}{|c|}{ Age in years } \\
\hline$<1$ & 11 & 10.1 & 1 & 0.9 & 31 & 28.4 & 43 & 39.4 \\
\hline 1 & 10 & 9.2 & 0 & 0.0 & 11 & 10.1 & 21 & 19.3 \\
\hline $2-4$ & 12 & 11.0 & 1 & 0.9 & 17 & 15.6 & 30 & 27.5 \\
\hline $5-6$ & 4 & 3.7 & 0 & 0.0 & 1 & 0.9 & 5 & 4.6 \\
\hline $7-9$ & 1 & 0.9 & 1 & 0.9 & 0 & 0.0 & 2 & 1.8 \\
\hline $10-19$ & 1 & 0.9 & 2 & 1.8 & 0 & 0.0 & 3 & 2.8 \\
\hline $20-29$ & 0 & 0.0 & 0 & 0.0 & 0 & 0.0 & 0 & 0.0 \\
\hline $30-39$ & 1 & 0.9 & 0 & 0.0 & 0 & 0.0 & 1 & 0.9 \\
\hline $40-49$ & 0 & 0.0 & 2 & 1.8 & 0 & 0.0 & 2 & 1.8 \\
\hline $50-59$ & 0 & 0.0 & 1 & 0.9 & 0 & 0.0 & 1 & 0.9 \\
\hline$\geq 60$ & 0 & 0.0 & 1 & 0.9 & 0 & 0.0 & 1 & 0.9 \\
\hline Deaths & 1 & 0.9 & 0 & 0.0 & 2 & 1.8 & 3 & 2.7 \\
\hline
\end{tabular}

two $(1.8 \%)$ in 7 - to 9-year-old children, three $(2.8 \%)$ in teens between 10 and 19 years, one $(0.9 \%)$ in adults from 30 to 39 years, two $(1.8 \%)$ in adults from 40 to 49 years, one $(0.9 \%)$ in adults from 50 to 59 years, and one $(0.9 \%)$ individual in older than 60 years group.

In total, 85 cases with negative result for the other seven respiratory viruses were fatal and distributed in the three years of the study: 49 in 2009, 15 in 2010, and 21 in 2011. In the analysis by age groups, eight $(9.6 \%)$ cases were observed in infants less than 1-year-old, 15 (18.1\%) in children aged 1 to 6 years, four $(4.8 \%)$ in adolescents aged 10 to 19 years, ten $(12.0 \%)$ in adults aged 20 to 29 years, nine (10.8\%) in adults aged 30 to 39 years, eleven (13.2\%) in adults aged 40 to 49 years, seventeen $(20.5 \%)$ in older people aged 50 to 59 years, and eleven $(13.2 \%)$ in people over 60 years. Of these, three cases $(3.5 \%)$ were positive for hMPV, and one occurred in 2009 and two in 2011. The case identified in 2009 was an immunosuppressed woman aged 36 years, and both cases in 2011 were infant males aged two and six months, respectively, and one of them had chronic heart disease.

\section{hMPV frequency in the three years of the study}

In 2009, hMPV infection was registered in 40 samples, including $33(82.5 \%)$ in children less than five years of age.
Among the remaining seven samples, only one was a fatal case detected in a patient aged 36 years. The analysis of the occurrence of hMPV along this year showed that it was detected between EW 32 and EW 50, with the peak of incidence $(n=29$, $72.5 \%$ ) in a period of five weeks (between EW 32 and EW 36).

In 2010, hMPV infection occurred in only nine samples $(\mathrm{n}=2,22.2 \%$ in less than five-year-old children). These cases were sporadically distributed in thirty weeks (EW 18 and EW 53) along the year. No fatal case was detected in any hMPVpositive patient.

In 2011, hMPV infection was registered in 60 samples $(\mathrm{n}=59,98.3 \%$ in less than five-year-old children), including two fatal cases (infants aged 2 and 6 months). Analysis of the occurrence of hMPV in a year showed that it was detected between EW 21 and EW 38, with the peak of incidence $(\mathrm{n}=51,85.0 \%)$ occurring in a period of nine weeks (between EW 26 and EW 35) (Figure 3).

\section{hMPV versus $\mathrm{hRSV}$ infection in the epidemiological weeks and age groups}

To understand the variation in respiratory virus dissemination over the years, hMPV and hRSV detection frequencies were compared in all EWs from 2009 to 2011 (Figure 3). The number 


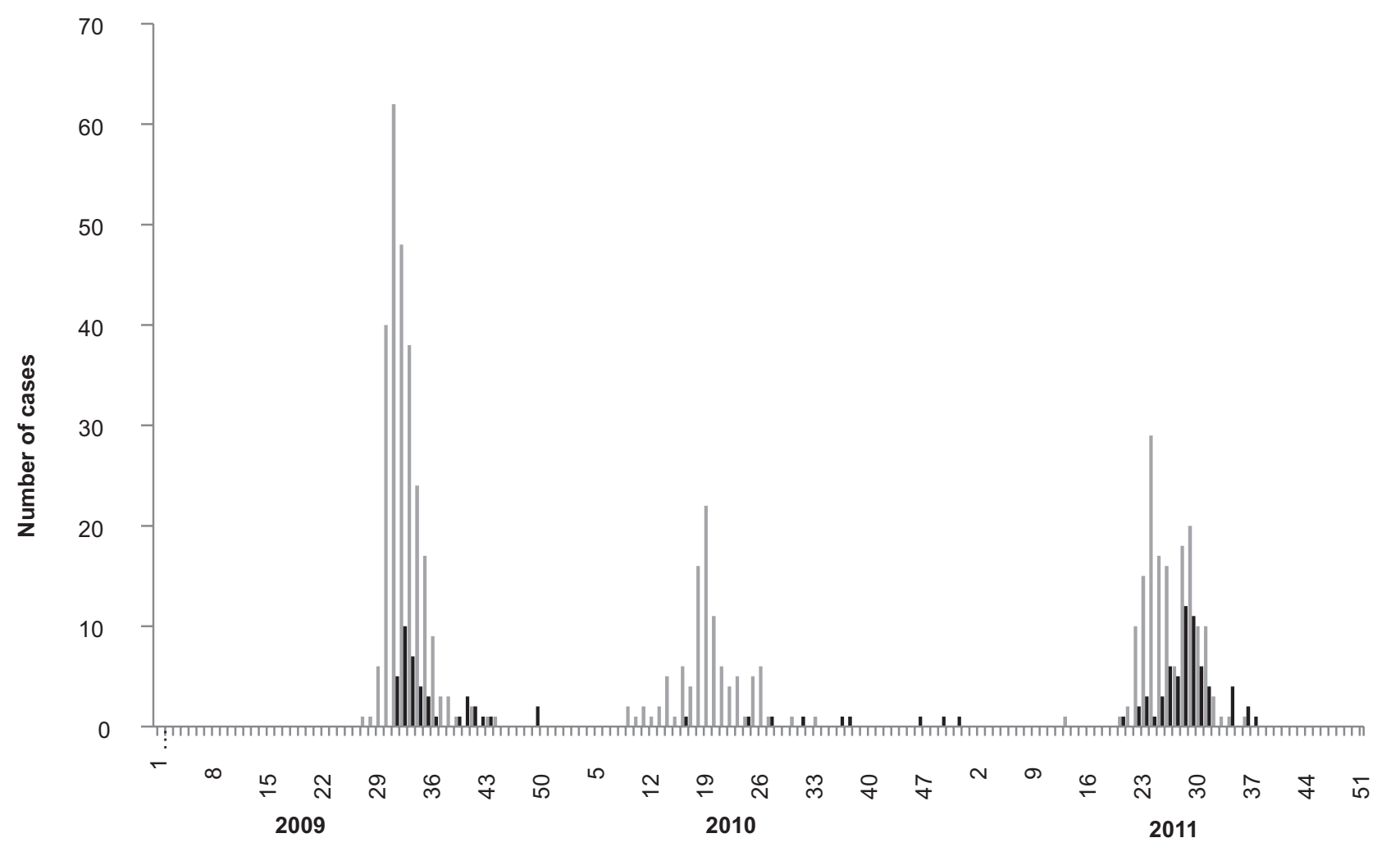

Weeks and epidemiological years of onset of symptoms

FIGURE 3: hRSV and hMPV infection cases of SARS according to epidemiological weeks in three years (2009, 2010, and 2011). hRSV: human respiratory syncytial virus; hMPV: human metapneumovirus; SARS: severe acute respiratory syndrome.

of hRSV was defined based on the results of IFA and registered LACEN/RS data. There were 562 (16.4\%) hRSV-positive samples in the 3,423 samples positive for at least one respiratory infection. hRSV was detected in $259(46.1 \%)$ patients in 2009, $124(22.6 \%)$ in 2010, and $179(31.8 \%)$ in 2011.

Human respiratory syncytial virus was detected between EW 29 and EW 44, highlighting a prominent incidence peak between EW 31 and EW 36 in 2009. This was the same period of hMPV occurrence, except for one hMPV-positive case in EW 50. In 2010, there was another hRSV incidence peak, but it occurred earlier and with less number of cases along the year (between EW 9 and EW 33) compared to that in 2009. Although four hMPV cases occurred in this time period, five more cases occurred in EWs after this hRSV peak. In 2011, hRSV and hMPV occurred almost simultaneously (with incidence peaks between EW 21 and EW 37), which was similar to that observed in 2009. It is noteworthy that the hMPV incidence peak was higher than those of the previous years with almost the same number of hRSV-positive cases.

The ages of the $\mathrm{hMPV}$ and $\mathrm{hRSV}$ patients were also evaluated. In total, 253 (45.1\%) hRSV cases were detected in children younger than 6 months, and the number of cases decreased gradually in the other age groups $(\mathrm{n}=130,23.2 \%$ in 6-11 monthold children; $n=84,15 \%$ in 1 -year-old children; $n=46,8.1 \%$ in 2-4 year-old children; $\mathrm{n}=10,1.8 \%$ in 5-9-year-old children; $\mathrm{n}=4,0.7 \%$ in $10-19$ year-old children; $\mathrm{n}=19,3.4 \%$ in other age groups). In contrast, hMPV infection presented frequencies more well-distributed in all age groups $(\mathrm{n}=31,28.6 \%$ in 6-11 monthold children; $n=16,14.5 \%$ in 1 -year-old children; $n=30,27.3 \%$ in 2-4-year-old children; $\mathrm{n}=4,3.9 \%$ in 5-9-year-old children; $\mathrm{n}=1,0.9 \%$ in $10-19$-year-old children; $\mathrm{n}=5,5.5 \%$ in other age groups) (Figure 4). Statistical comparison showed that hRSV was significantly more frequent in children less than 6 months of age $(\mathrm{n}=253 ; 45 \%$ vs. $\mathrm{n}=21 ; 19 \% ; \mathrm{p}<0.01)$, whereas hMPV was more prevalent in 2- and 4 year-old children $(\mathrm{n}=152 ; 27 \%$ vs $\mathrm{n}=9 ; 8 \% ; \mathrm{p}<0.01)$. The frequencies of these viruses were not significantly different in other age groups $(\mathrm{p}>0.05)$.

\section{hMPV versus hRSV symptoms}

To understand the clinical manifestations of SARS according to viral infection, symptoms of hMPV- and hRSVpositive patients were comparatively analyzed. Patients with hMPV usually presented with fever $(n=523,95.9 \%)$, dyspnea 


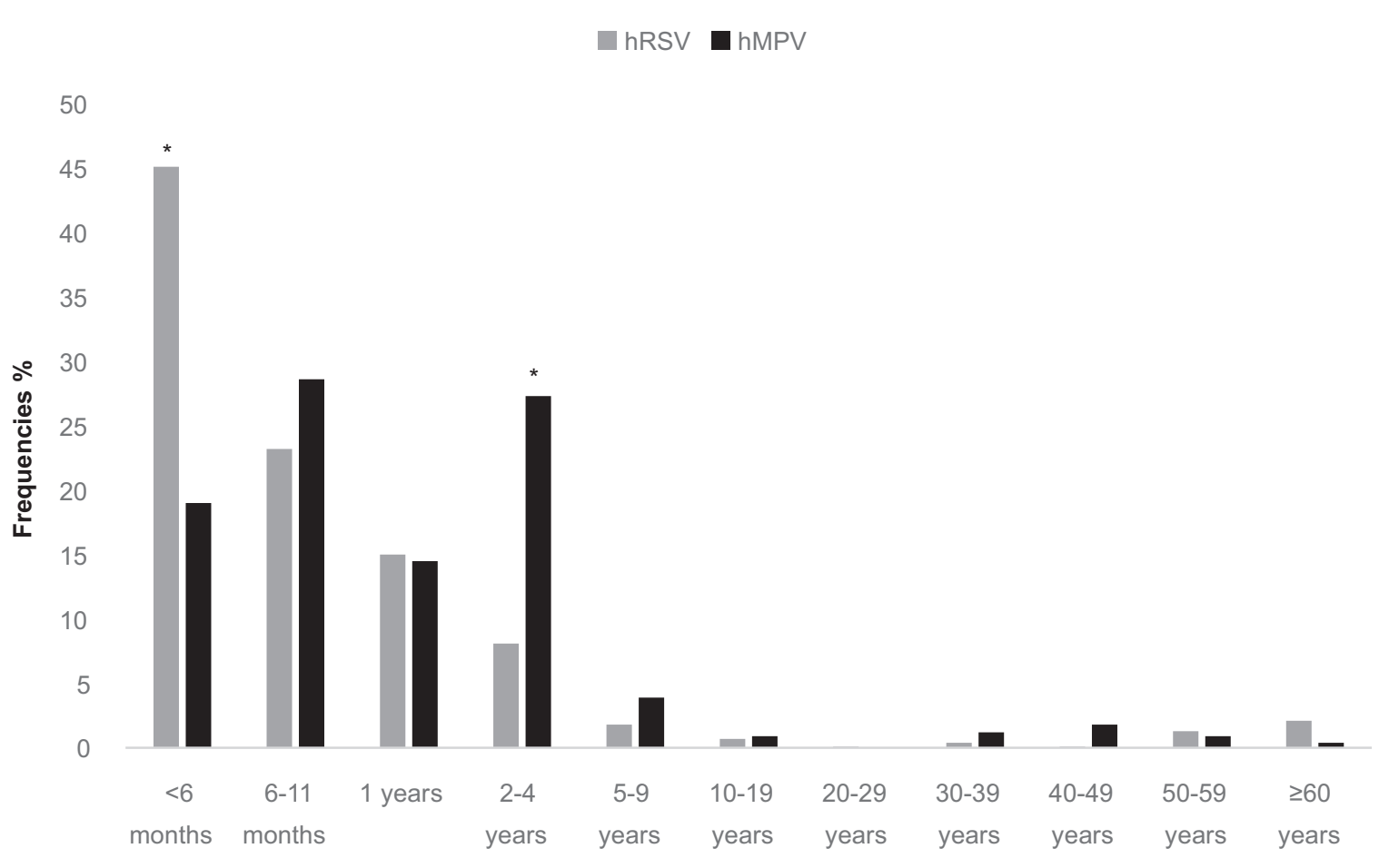

Age groups

FIGURE 4: hRSV and hMPV infection cases of SARS according to age groups. hRSV: human respiratory syncytial virus; hMPV: human metapneumovirus; SARS: severe acute respiratory syndrome. ${ }^{*}$ Indicates significant difference $(p-v a l u e s<0.05)$.

$(\mathrm{n}=472 ; 86.6 \%)$, cough $(\mathrm{n}=468,85.9 \%)$, and coryza $(\mathrm{n}=359$; $85.9 \%$ ). hRSV symptoms were similar (but in a slightly different order): cough $(\mathrm{n}=527 ; 93.7 \%)$, fever $(\mathrm{n}=519 ; 92.4 \%)$, dyspnea $(\mathrm{n}=477 ; 84.8 \%)$, and coryza $(\mathrm{n}=412 ; 73.4 \%)$. The frequency of occurrence of the main symptoms as well as arthralgia $(2.4 \%$ vs $3.8 \%)$ and diarrhea $(10.0 \%$ vs $13.9 \%)$ did not vary significantly between these two viral infections (all $p$-values $>0.05$ ) (Figure 5). In contrast, myalgia, conjunctivitis, sore throat, and chill were significantly more frequent in hRSV- than in hMPVpositive cases (all $p$-values $<0.05$ ).

\section{DISCUSSION}

Brazil is a large country with five geographic regions, each with unique climate characteristics. Rio Grande do Sul is a state located in South Brazil and divided into several geographic regions with subtropical and humid climate. Respiratory infections are important public health problems in this state, since it presents one of the coldest climates of the country ${ }^{14,15,35}$. The present study demonstrated that hMPV circulated mainly in EWs in the winter and in the beginning of spring in 2009, 2010, and 2011. This finding is in agreement with the results of previous studies in southern Brazil that detected hMPV mostly in this same period of the year ${ }^{14,36,37}$.

The frequency of occurrence of different human viral respiratory infections is important to define public health policies over the years. The overall hMPV infection frequency observed in this study was $20 \%(\mathrm{n}=109$ cases in 545 SARS cases, with negative result for all other respiratory viruses). Studies have reported variable frequencies of hMPV infection in Brazil. For example, in South Brazil, previous reports indicated values of $6.4 \%$ and $14.5 \%{ }^{14,16}$. Studies conducted in the southeast and northeast regions of the country also reported similar frequencies (12.3\% in Minas Gerais, $5.6 \%$ in São Paulo, and $5.9 \%$ in the four capital cities of Northeastern Brazilian states) ${ }^{17-19}$. Despite the different climatic conditions in Brazil, hMPV frequencies do not vary significantly, albeit with a subtle increase in the southern region (the coldest in the country). Identical frequency ranges of hMPV infection in cases of SARS was observed in other South American countries ${ }^{20-23,38}$.

hMPV occurrence in subregions of the Rio Grande do Sul state was determined to evaluate the dissemination of hMPV in the southernmost region of Brazil. The majority of the hMPVinfected patients lived in the Metropolitan/East region, the most populous region of the state, which is also home to the Central Laboratory of the Rio Grande do Sul state (LACEN/RS). This is in agreement with the results of previous studies conducted in this state ${ }^{14,36,37}$.

hMPV infection is usually more frequently detected in children with less than one-year-old (mean ages ranging from 4.4 to 5.9 months) ${ }^{14,16,18}$. In the present study, there was 


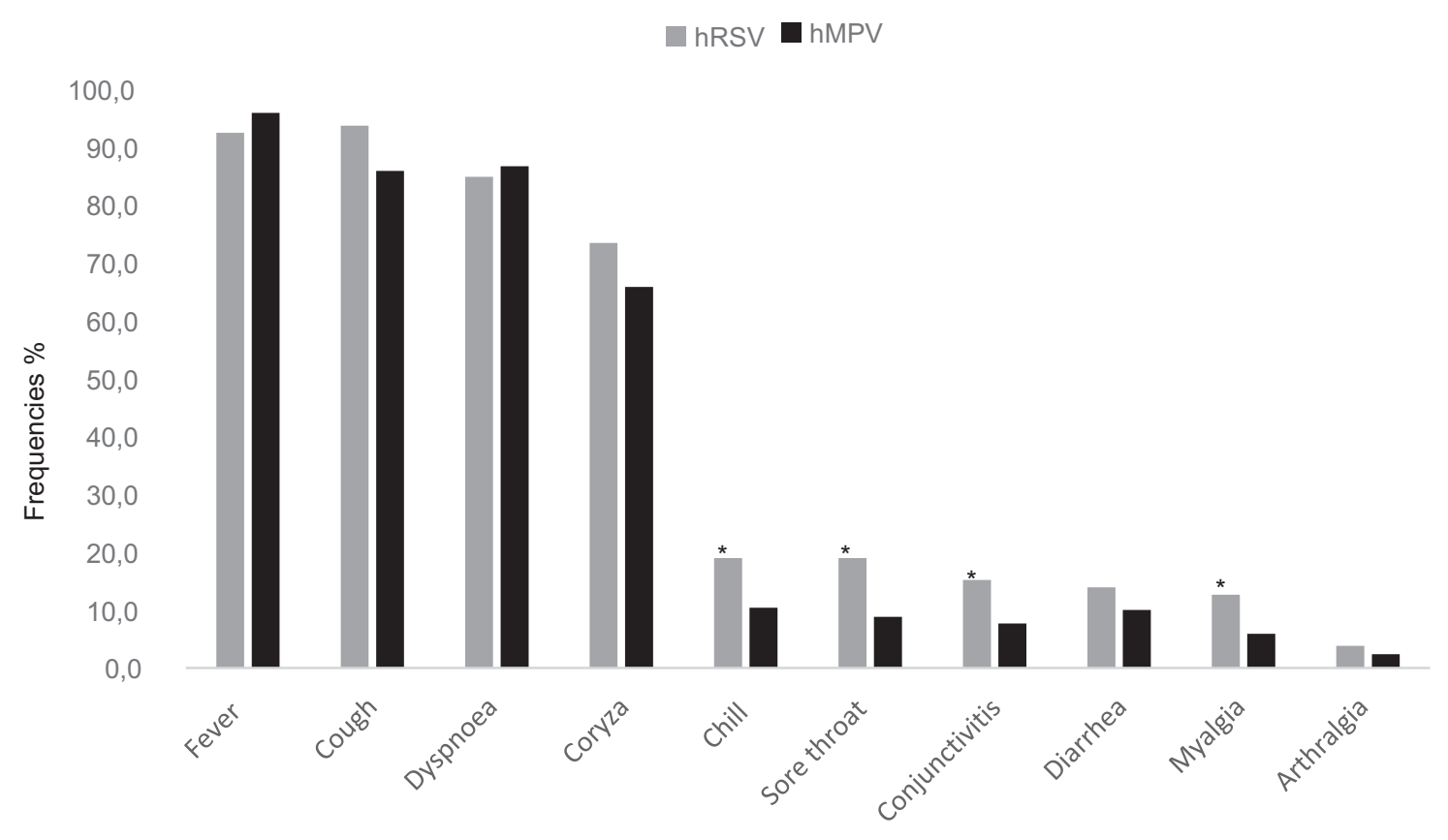

Clinical symptoms

FIGURE 5: hRSV and hMPV infection cases of SARS according to main respiratory symptoms. hRSV: human respiratory syncytial virus; hMPV: human metapneumovirus; SARS: severe acute respiratory syndrome. *Indicates significant difference $(p-v a l u e s<0.05)$.

a high frequency of hMPV infection in this age range $(45.7 \%)$. However, hMPV occurrence was less frequent in one-year old children than hRSV as also observed by a previous study ${ }^{39}$.

Interestingly, hMPV infection presented a variable frequency in the three years of the study $(36.7 \%$ in $2009,8.3 \%$ in 2010 , and $55 \%$ in 2011) in SARS patients without any other viral infection. These results suggest the rate of hMPV dissemination varies with the year of occurrence. Previous studies have also reported alternating epidemiological profiles of hMPV infection in Europe $^{10,12,40}$. Interestingly, these studies presented a phenomenon characterized by one year of high hMPV dissemination followed by another year of low dissemination; however, the cause of this biannual periodicity remains unknown ${ }^{40}$.

The seasonal distribution of hMPV and hRSV was also compared, demonstrating a similar temporal dissemination of both viruses in winter and spring in 2009 and 2011. In 2010, hMPV infections occurred throughout three seasons (autumn, winter, and spring), whereas hRSV presented the same incidence peak as observed in the other years. hMPV infections occur throughout the year; however, more cases have been detected in winter and spring in other studies ${ }^{15,40,41}$. Therefore, the seasonal occurrence of hMPV appears to coincide with hRSV infections ${ }^{37,39,42,43}$. However, hMPV and hRSV frequencies vary over the years, which is in agreement with previous findings ${ }^{37,43}$.

Oscillations in hMPV and hRSV prevalence are consistent with those observed for other respiratory viruses, but it is not clear if this was coincidence or a real pattern ${ }^{10}$. In 2010, hMPV presented the lowest seasonal activity in the period studied for three consecutive years (2009-2011). In this influenza postpandemic year, other respiratory viruses also presented low prevalence probably due to the vaccination campaign for influenza A/H1N1pdm09 in March 2010, leading low notification of suspected cases and consequently, decrease in the frequency of occurrence of other respiratory viruses (influenza, PIV, and ADV). The year 2011 was characterized by both highest prevalence and seasonal circulation of hMPV. The peak occurred in the EWs 29 and 30, which was preceded by a decrease of average daily temperatures in Rio Grande do Sul, with temperatures ranging from 2.18 to $24.4^{\circ} \mathrm{C}$ (mean $14.06^{\circ} \mathrm{C}$ ) in winter ${ }^{35}$.

In the present study, we identified 85 cases of deaths that were negative for seven respiratory viruses (influenza A, influenza B, hRSV, ADV, and PIV 1, 2, and 3). Of these cases, three $(3.5 \%)$ were positive for hMPV, which included one immunocompromised woman and two children with chronic heart diseases. Although it is not possible to definitely ascertain the etiological origin of these SARS cases, hMPV was the only detected virus and a probable candidate responsible for the respiratory disease in these patients. Therefore, it is important to broadly assess the possible SARS-related pathogens, especially in cases with associated comorbidities ${ }^{1,2}$.

This study has some limitations. The sampling population was selected by convenience among SARS-notified cases and 
it does not represent the entire exposed population. In addition, the symptoms were collected by a standard questionnaire for influenza and did not precisely represent the hMPV clinical spectrum. Further, positive samples for the other seven respiratory viruses were not tested, and therefore, co-infections could not be detected, which might affect the real number of hMPV in the samples evaluated. Finally, detection tests for human rhinovirus, enterovirus, coronavirus, and bocavirus were not performed to expand the screening of SARS pathological agents.

Nonetheless, the present data are based on patients attending the most important region in southern Brazil (including 204 hospitals in all regions of the Rio Grande do Sul State) and provide critical epidemiological knowledge regarding respiratory infections caused by hMPV in a three-year period. More studies are required to better characterize hMPV dissemination for defining public health policies. Furthermore, hMPV should be added to the panel of viruses tested for the routine detection of infectious viral respiratory diseases in this Brazilian region.

In conclusion, hMPV was detected in $20 \%$ patients with SARS (mainly children) without other detectable viral infection, showing that $\mathrm{hMPV}$ is an important respiratory pathogen in southern Brazil. Therefore, it is necessary to include hMPV detection as a differential diagnosis for viral respiratory illness.

\section{Acknowledgements}

We thank Gabriela Tumioto Giannini for assistance with data from Instituto Nacional de Pesquisas Espaciais (INPE).

\section{Conflict of interest}

The authors declare that there is no conflict of interest.

\section{Financial support}

This study was supported by Instituto de Pesquisas Biológicas-Laboratório Central (IPB-LACEN/RS) and Universidade Luterana do Brasil (ULBRA).

\section{REFERENCES}

1. Panda S, Mohakudb NK, Penac L, Kumar S. Human metapneumovirus: review of an important respiratory pathogen. Int J Infect Dis. 2014;25:45-52.

2. Kahn JS. Epidemiology of human metapneumovirus. Clin Microbiol Rev. 2006;19(3):546-57.

3. World Health Organization (WHO). Global Influenza Surveillance Network. Manual for the laboratory diagnosis and virological surveillance of influenza. Geneva, Switzerland: WHO; 2011. 153p. [update 2011]. Available from: http://apps.who.int/iris/ bitstream/10665/44518/1/9789241548090_eng.pdf

4. Syrmis MW, Whiley DM, Thomas M, Mackay IM, Williamson J, Siebert DJ, et al. A sensitive, specific, and cost-effective multiplex reverse transcriptase-PCR assay for the detection of seven common respiratory viruses in respiratory samples. J Mol Diagn. 2004;6(2):125-31.

5. Quan P L, Palacios G, Jabado OJ, Conlan S, Hirschberg DL, Pozo F, et al. Detection of respiratory viruses and subtype identification of influenza A viruses by GreenChipResp oligonucleotide Microarray. J Clin Microbiol. 2007;45(8):2359-64.

6. Lambert SB, Allen KM, Sloots TP, Nissen MD, Nolan TM. Human metapneumovirus and human coronavirus NL63. In reply. Pediatrics. 2008;121(2):446-7.

7. Scott JA, Brooks WA, Peiris JS, Holtzman D, Mulholland EK. Pneumonia research to reduce childhood mortality in the developing world. J Clin Invest. 2008;118(4):1291-300.

8. Costa LF, Yokosawa J, Mantese OC, Oliveira TFM, Silveira HL, Nepomuceno LL, et al. Respiratory viruses in children young than five years old with acute respiratory disease from 2001 to 2004 in Uberlândia, MG, Brazil. Mem Inst Oswaldo Cruz. 2006;101(3): 301-6.

9. Gardinassi LG, Marques Simas PV, Salomão JB, Durigon EL, Zanetta Trevisan DM, Cordeiro JA, et al. Seasonality of viral respiratory infections in southeast of Brazil: the influence of temperature and air humidity. Braz J Microbiol. 2012;43(1):98-108.

10. Schildgen V, van den Hoogen B, Fouchier R, Tripp RA, Alvarez R, Manoha C, et al. Human metapneumovirus: lessons learned over the first decade. Clin Microbiol Rev. 2011;24(4):734-54.

11. Cuevas LE, Nasser AM, Dove W, Gurgel RQ, Greensill J, Hart CA. Human metapneumovirus and respiratory syncytial virus, Brazil. Emerg Infect Dis. 2003;9(12):1626-8.

12. Maggi F, Pifferi M, Vatteroni M, Fornai C, Tempestini E, Anzilotti $\mathrm{S}$, et al. Human metapneumovirus associated with respiratory tract infections in a 3-year study of nasal swabs from infants in Italy. J Clin Microbiol. 2003;41(7):2987-91.

13. Mahalingam S, Schwarze J, Zaid A, Nissen M, Sloots T, Tauro S, et al. Perspective on the host response to human metapneumovirus infection: what can we learn from respiratory syncytial virus infections? Microbes Infect. 2006;8(1):285-93.

14. Pilger DA, Cantarelli VV, Amantea SL, Leistner-Segal S. Detection of human bocavirus and human metapneumovirus by real-time PCR from patients with respiratory symptoms in Southern Brazil. Mem Inst Oswaldo Cruz. 2011;106(1):56-60.

15. Wolf JM, Gregianini TS, Seadi CMF, Tumioto GL, Dambrós BP, Lehmann FKM, et al. Performance of direct immunoflorescence assay for the detection of human metapneumovirus under clinical laboratory settings. Rev Soc Bras Med Trop. 2015;48(6):762-4.

16. do Carmo Debur M, Bordignon J, Duarte dos Santos CN, Vidal LR, Nogueira MB, de Almeida SM, et al. Acute respiratory infection by humanmetapneumovirus in children in southern Brazil. J Clin Virol. 2007;39(1):59-62.

17. Carneiro BM, Yokosawa J, Arbiza J, Costa LF, Mirazo S, Nepomuceno LL, et al. Detection of all four human metapneumovirus subtypes in nasopharyngeal specimens from children with respiratory disease in Uberlândia, Brazil. J Med Virol. 2009;81(10):1814-8.

18. Da Silva LH, Spilki FR, Riccetto AG, de Almeida RS, Baracat EC, Arns CW. Variant isolates of human metapneumovirus subgroup B genotype 1 in Campinas, Brazil. J Clin Virol. 2008;42(1):78-81.

19. Gurgel RQ, Bezerra PG, Duarte MC, Moura AA, Souza EL, Silva LS, et al. Relative frequency, possible risk factors, viral codetection rates, and seasonality of respiratory syncytial virus among children with lower respiratory tract infection in Northeastern Brazil. Medicine (Baltimore). 2016;95(15):e3090.

20. Galiano M, Videla C, Puch SS, Martínez A, Echavarría M, Carballal G. Evidence of human metapneumovirus in children in Argentina. J Med Virol. 2004;72(2):299-303.

21. Luchsinger V, Escobar C, Avendaño LF. Detection of human metapneumovirus in children hospitalized for acute lower respiratory infection in Santiago, Chile. Rev Med Chil. 2005;133(9):1059-64. 
22. Wu A, Budge PJ, Williams J, Griffin MR, Edwards KM, Johnson M, et al. Incidence and risk factors for respiratory syncytial virus and human metapneumovirus infections among children in the remote highlands of Peru. PLoS One. 2015;24,10(6):e0130233.

23. Rodriguez PE, Adamo MP, Paglini MG, Moreno L, Camara JA, Camara A. Monoinfection of human metapeumovirus in Cordoba: first clinical and epidemiological research in children with respiratory infection in 2011. Rev Fac Cien Med Univ Nac Cordoba. 2016;73(3):170-5.

24. Williams JV, Martino R, Rabella N, Otegui M, Parody R, Heck JM, et al. A prospective study comparing human metapneumovirus with other respiratory viruses in adults with hematologic malignancies and respiratory tract infections. J Infect Dis. 2005;192(6):1061-5.

25. Dokos C, Masjosthusmann K, Rellensmann G, Werner C, SchulerLüttmann S, Müller KM, et al. Fatal human metapneumovirus infection following allogeneic hemato-poietic stem cell transplantation. Transpl Infect Dis. 2013;15(3):E97-E101.

26. Matsuda S, Nakamura M, Hirano E, Kiyota N, Omura T, Suzuki Y, et al. Characteristics of human metapneumovirus infection prevailing in hospital wards housing patients with severe disabilities. Jpn J Infect Dis. 2013;66(3):195-200.

27. Boivin G, Abed Y, Pelletier G, Ruel L, Moisan D, Cote S, et al. Virological features and clinical manifestations associated with human metapneumovirus: a new paramyxovirus responsible for acute respiratory-tract infections in all age groups. J Infect Dis. 2002;186(9):1330-4.

28. Silva LHA, Spilki FR, Riccetto AGL, Baracat ECE, Arns CW. Human respiratory syncytial virus and human metapneumovirus. Rev HCPA. 2009;29(2):139-46.

29. Kesson AM. Respiratory virus infections. Paediatr Respir Rev. 2007;8(3):240-8.

30. Jafri HS, Ramilo O, Makari D, Charsha-May D, Romero JR. Diagnostic virology practices for respiratory syncytial virus and influenza virus among children in the hospital setting: a national survey. Pediatr Infect Dis J. 2007;26(10):956-8.

31. Tollefson SJ, Cox RG, Williams JV. Studies of culture conditions and environ-mental stability of human metapneumovirus. Virus Res. 2010;151(1):54-9.

32. Bharaj P, Sullender WM, Kabra SK, Mani K, Cherian J, Tyagi V, et al. Respiratory viral infections detected by multiplex PCR among pediatric patients with lower respiratory tract infections seen at an urban hospital in Delhi from 2005 to 2007. Virol J. 2009;6:89.

33. Marx C, Gregianini TS, Lehmann FK, Lunge VR, Carli Sd, Dambrós BP, et al. Oseltamivir-resistant influenza A(H1N1)pdm09 virus in southern Brazil. Mem Inst Oswaldo Cruz. 2013;108(3): 392-4.

34. Kim C, Ahmed JA, Eidex RB, Nyoka R, Waiboci LW, Erdman D, et al. Comparison of nasopharyngeal and oropharyngeal swabs for the diagnosis of eight respiratory viruses by real-time reverse transcription-PCR assays. PLoS One. 2011;6(6):e21610.

35. Ministério da Agricultura, Pecuária e Abastecimento. Instituto Nacional de Meteorologia (INMET). Banco de Dados Meteorológicos para Ensino e Pesquisa (BDMEP). Brasília: INMET; 2017. Disponível em: http://www.inmet.gov.br/portal/ index.php?r=bdmep/bdmep

36. Straliotto SM, Gregianini TS, Baccin TG, Motta FC, Siqueira MM. Influenza virus detected in the State of the Rio Grande do Sul, Brazil, during 2006 and 2007. Boletim da Saúde. 2009;23(1): 57-62.

37. Straliotto SM, Siqueira MM, Muller RL, Fischer GB, Cunha ML, Nestor SM. Viral etiology of acute respiratory infections among children in Porto Alegre, RS, Brazil. Rev Soc Bras Med Trop. 2002;35(4):283-91.

38. Escobar C, Luchsinger V, de Oliveira DB, Durigon E, Chnaiderman J, Avendaño LF. Genetic variability of human metapneumovirus isolated from Chilean children, 2003-2004. J Med Virol. 2009;81(2):340-4.

39. Davis RC, Stockmann C, Pavia AT, Byington LC, Blaschke AJ, Hersh AL, et al. Incidence, morbidity, and costs of human metapneumovirus infection in hospitalized children. J Pediatric Infect Dis Soc. 2015;5(3):303-11.

40. Aberle SW, Aberle JH, Sandhofer MJ, Pracher E, Popow-Kraupp T. Biennial spring activity of human metapneumovirus in Austria. Pediatr Infect Dis J. 2008;27(12):1065-8.

41. Debur MC, Vidal LR, Stroparo E, Nogueira MB, Almeida SM, Takahashi GA, et al. Impact of human metapneumovirus infection on in and outpatients for the years 2006-2008 in Southern Brazil. Mem Inst Oswaldo Cruz. 2010;105(8):1010-8.

42. Chan PC, Wang CY, Wu PS, Chang PY, Yang TT, Chiang YP, et al. Detection of human metapneumovirus in hospitalized children with acute respiratory tract infection using real-time RT-PCR in a hospital in northern Taiwan. J Formos Med Assoc. 2007;106(1): 16-24.

43. Serafino RL, Gurgel RQ, Dove W, Hart CA, Cuevas LE. Respiratory syncytial virus and metapneumovirus in children over two seasons with a high incidence of respiratory infections in Brazil. Ann Trop Paediatr. 2004;24(3):213-7. 